\title{
A Dicationic Iminophosphane
}

\author{
Ying Kai Loh, Chitra Gurnani, Rakesh Ganguly, and Dragoslav Vidović* \\ Department of Chemistry and Biological Chemistry, Nanyang Technological University, 21 Nanyang Link, Singapore, \\ 637371.
}

Supporting Information Placeholder

\begin{abstract}
A novel dicationic system containing a PN fragment has been synthesized and structurally characterized. According to the solid state analysis and theoretical investigation the dicationic iminophosphane resonance from is the most appropriate description for the dication. However, the contribution from the phosphorus mononitride resonance form is not negligible.
\end{abstract}

Neutral two-eletron donor carbenes have proven to be quite versatile ligands for isolation of a wide variety of novel main group species. ${ }^{1-4}$ Examples include diatomic allotropes ( $\mathrm{L}_{-} \mathrm{E}_{2}-\mathrm{L} ; \mathrm{L}=$ carbene, $\mathrm{E}=\mathrm{B}, \mathrm{Si}, \mathrm{Ge}, \mathrm{P}, \mathrm{As}$, etc $)^{1 \mathrm{a}}$ of boron, silicon, germanium, phosphorus, arsenic, etc. ${ }^{2-4}$ Nevertheless, these interesting molecules, among numerous other main group species, sparked a debate about the most appropriate way to describe bonding in these compounds. ${ }^{5,6}$ In particular, the arguments have been focused on whether the carbene moieties form typical covalent bonds or the use of dative bond analogy is also valid. The latest evidence showed that the L-E bonds for $\mathrm{L}_{-} \mathrm{B}_{2}-\mathrm{L}$ are quite strong suggesting a substantial covalent character. ${ }^{6}$ However, Frenking argued that dative bonds could be also very strong by the combination of $\sigma$-donation from $\mathrm{L}$ and $\pi$-back bonding from the $\mathrm{E}_{2}$ fragment in this case. ${ }^{5 \mathrm{~b}}$

The same bonding arguments would also apply to the recently synthesized heteronuclear PN fragment stabilized by two carbene moieties (A, Figure 1). ${ }^{7}$ The authors of this work describe it as a carbene-stabilized phosphorus mononitride or phosphinidenenitrene ( $\mathbf{A}^{\prime}$ ) but did acknowledge that the phosphazabutadiene (A') description was also appropriate. Furthermore, single electron oxidation of $\mathbf{A}$ was demonstrated to form its radical cation $\mathbf{B}$. On the other hand, double oxidation was not to be feasible with this system even though successful two-electron oxidations were achieved with the $\mathrm{P}$ and As homonuclear analogues. ${ }^{4 c, e}$ This was presumably due to (i) the polarized nature of the $\mathrm{P}-\mathrm{N}$ bond and (ii) the $\pi$-accepting properties of the carbenes particularly of the cyclic alkyl amino carbene (CAAC). ${ }^{8}$ It was then conceivable that the use of a good $\pi$-donor would provide sufficient electronic stabilization for the preparation of the doubly oxidized from of A that was predicted to have a $\mathrm{P}=\mathrm{N}$ double bond. ${ }^{9}$ Carbones $^{10,11}$ (C, Figure 1), which are neutral four-electron donors, certainly fit this description as they possess simultaneous $\sigma$ and $\pi$-donor properties making them ideal ligands for the isolation of exceptionally electron-deficient species. ${ }^{12}$ In this work, we wish to report the use of a carbonecarbene synergy for the stabilization of the doubly oxidized analogue of $\mathbf{A}$ whose structural parameters and the frontier orbitals indicated the formation of the first example of a dicationic iminophosphane. However, dicationic phosphorus mononitride description for this molecule should not be completely dismissed.

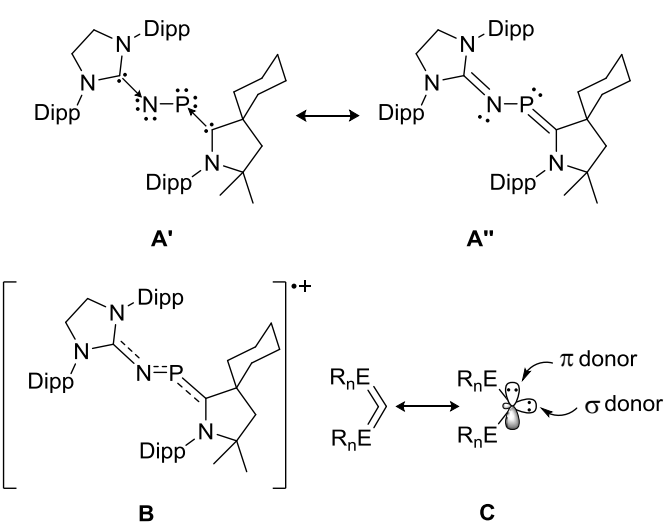

Figure 1. Recently isolated neutral (A) and radical cationic (B) phosphorus mononitrides, and general structure for carbones (C). Dipp = 2,6-diisopropylphenyl.

The overall synthesis of the target dication is summarized in Scheme 1. The initial P-N bond was formed by trimethylsilyl chloride elimination upon treating imine 1 with $\mathrm{PCl}_{3}$. The resulting phosphine 2 was then subjected to chloride displacement using carbodiphosphorane 3 to form $4[\mathrm{Cl}]$. The ${ }^{31} \mathrm{P}$ NMR spectrum of $4[\mathrm{Cl}]$ contained two second order signals observed at 21.8 and 262.5 $\mathrm{ppm}$. The latter signal was assigned to the central $\mathrm{P}$ which was more than $130 \mathrm{ppm}$ downfield shifted with respect to $\left[{ }^{i} \mathrm{Pr}_{2} \mathrm{NP}(\mathrm{Cl})\left(\mathrm{C}\left(\mathrm{PPh}_{3}\right)_{2}\right)\right][\mathrm{Cl}](\delta \mathrm{P}=133.4 \mathrm{ppm}) .{ }^{12 \mathrm{c}}$ After structural elucidation of $4[\mathrm{Cl}]^{13}$ (Figure 2 ) the unexpected downfield shift of this $\delta \mathrm{P}$ signal was attributed to the elongated nature of the $\mathrm{P} 1-\mathrm{Cl} 1$ bond of $\mathbf{4}^{+}(2.3472(16) \AA)$ with respect to $\left[\mathrm{i}_{2} \mathrm{NP}(\mathrm{Cl})\left(\mathrm{C}\left(\mathrm{PPh}_{3}\right)_{2}\right)\right]^{+}$ (2.173(2) $\AA$ ). ${ }^{14}$ This observation also hinted at incipient ionization towards the target dication.

Indeed, the addition of 2 equiv of $\mathrm{AgSbF}_{6}$ to a 1,2-difluorobenzene solution containing $4[\mathrm{Cl}]$ resulted in immediate color change from yellow to orange yielding $5\left[\mathrm{SbF}_{6}\right]_{2}$. The $\delta \mathrm{P}$ signal assigned to the central $\mathrm{P}$ was observed at $410.2 \mathrm{ppm}$ which is more than $50 \mathrm{ppm}$ downfield shifted from $\left[\mathrm{Pr}_{2} \mathrm{NP}\left(\mathrm{C}\left(\mathrm{PPh}_{3}\right)_{2}\right)\right]^{2+}\left(\delta_{\mathrm{P}}=355.7 \mathrm{ppm}\right)$ but well within the range observed for similar two-coordinate phosphorus species. ${ }^{15,16}$ The expected coordination geometry around the central P and the trans-bent C1-P1-N1-C2 fragment (torsion angle $=171.8^{\circ 17}$ ) of the newly formed species were confirmed by single crystal X-ray diffraction (Figure 2).

As predicted, the P1-N1 bond length of 1.594(6) $\AA$ for $\mathbf{5}\left[\mathrm{SbF}_{6}\right]_{2}$ was shorter than the same distances observed for neutral $\mathbf{A}$ $(1.7085(16) \AA)$ and its radical cation B $(1.645(4) \AA) .{ }^{7}$ In fact, this bond distance for $\mathbf{5}\left[\mathrm{SbF}_{6}\right]_{2}$ is well within the range for the analogous bond distances observed for iminphosphanes that contain doubly bonded PN fragments. ${ }^{16}$ The observed trend may be 
Scheme 1. General synthetic protocol.

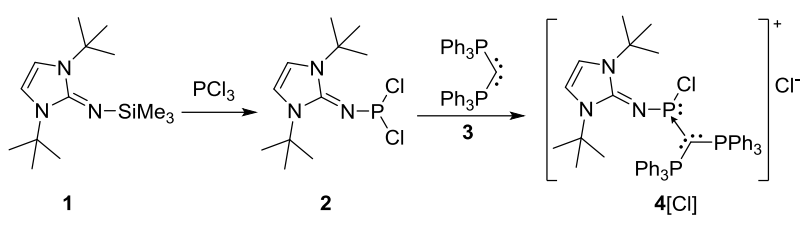

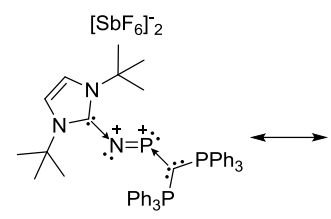

$\mathbf{5 b}\left[\mathrm{SbF}_{6}\right]_{2}$

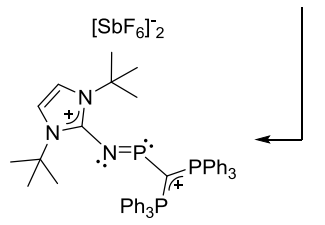

$5 \mathrm{a}\left[\mathrm{SbF}_{6}\right]_{2}$ described as the stepwise removal of an electron pair from the HOMO of $\mathbf{A}$ which is a PN $\pi^{*}$ antibonding orbital resulting in an increase in bond order from 1 to $2 .{ }^{7}$ This supports the depiction of $\mathbf{5}^{\mathbf{2 +}}$ as a doubly oxidized analogue of $\mathbf{A}$. Electron depletion at the PN fragment for $\mathbf{5}^{\mathbf{2}}$ was also apparent by a longer N1-C2 bond distance $(1.367(8) \AA$ ) and a larger P1-N1-C2-N2 torsion angle $\left(55.5^{\circ}\right)$ in comparison to the analogous values for both $\mathbf{A}(1.282(3)$ and $\left.10.1^{\circ}\right)$ and $\mathbf{B}\left(1.313(5)\right.$ and $\left.32.1^{\circ 17}\right)$. This is presumably due to the decrease in $\pi$-backdonation from the increasingly electron-deficient PN fragment to the carbene, weakening the N1-C2 bond. In fact, this $\mathrm{N}-\mathrm{C}$ bond distance for $\mathbf{5}^{\mathbf{2}}$ is not only within the range for a single $\mathrm{N}-\mathrm{C}\left(\mathrm{sp}^{2}\right)$ bond ${ }^{18}$ but is also the longest $\mathrm{N}-\mathrm{C}$ bond with respect to similar compounds (including $\mathbf{A}$ and $\mathbf{B}$ ) containing a "guanidyl" moiety. ${ }^{19}$

Furthermore, the P1-C1 bond distance for $\mathbf{5}^{\mathbf{2 +}}(1.748(7) \AA)$, which was found to fall between the P-C bond distances for $\mathbf{A}$ $(1.719(2) \AA)$ and its radical cation $\mathbf{B}(1.788(5) \AA)$, was essentially identical to the analogous bond distance for $\left[{ }^{[} \operatorname{Pr}_{2} \mathrm{NP}\left(\mathrm{C}\left(\mathrm{PPh}_{3}\right)_{2}\right)\right]^{2+}$ (1.745(7) $\AA$ ). This observation together with the co-planarity of the carbone with the PN moiety $\left(\mathrm{N} 1-\mathrm{P} 1-\mathrm{C} 1-\mathrm{P} 2\right.$ torsion angle $\left.=1.2^{\circ}\right)$ was expected as the creation of the electron-deficient PN fragment was compensated by an increase in the $\mathrm{C} 1 \rightarrow \mathrm{P} 1 \pi$ donation. In fact, it was believed that the ability of the carbone $\mathbf{3}$ to $\pi$ donate to the central $\mathrm{P}$ was crucial for the overall stability of the dication $\mathbf{5}^{\mathbf{2}}$. Even though a close $\mathrm{P} \cdots \mathrm{F}$ interion contact was observed $(3.04 \AA$; the sum of the van der Walls radii for $\mathrm{P}$ and $\mathrm{F}$ is $3.36 \AA^{20}$ ), it should not have any drastic consequences on the observed structural parameters for $\mathbf{5}^{\mathbf{2 +}} .{ }^{21}$ In fact, close interion contacts are virtually nonexistent in solution as the synthesis of $\mathbf{5}^{2+}$ in the presence of $\mathrm{AlCl}_{4}$ and $\left[\mathrm{BAr}_{4}\right]^{-}\left(\mathrm{Ar}^{\mathrm{f}}=3,5-\left(\mathrm{CF}_{3}\right)-\mathrm{C}_{6} \mathrm{H}_{3}\right)$ had no effect on the value for the $\delta_{\mathrm{P}}$ signal assigned to the central $\mathrm{P}$.

Thus, the abovementioned structural parameters (the PN bond distance, the CPNC torsion angle, etc.) for $\mathbf{5}^{\mathbf{2}+}$ are very similar to analogous parameters observed for neutral iminophosphane containing electron donating substituents ${ }^{16}$ implying that the resonance form $\mathbf{5} \mathbf{a}^{2+}$ is the most adequate when describing this molecule.

Further insights into the bonding motif for the dicationic moiety of $\mathbf{5}\left[\mathrm{SbF}_{6}\right]_{2}$ was gained by performing density functional theory (DFT) calculations using the Gaussian 09 package. The structure was optimized at the B3LYP/6-31G(d) level of theory yielding a close match between the theoretical and experimental structural parameters. The HOMO and the LUMO (B3LYP/6-311G(d)) for the dication $\mathbf{5}^{\mathbf{2}}$ are depicted in Figure 3 . As expected the LUMO of $\mathbf{5}^{\mathbf{2}}$ (antibonding for the PN fragment) is virtually equivalent to the HOMO of $\mathbf{A}$ and the SOMO of $\mathbf{B}$ while the HOMO of $\mathbf{5}^{\mathbf{2}}$ is exactly the same as the HOMO-1 of $\mathbf{A}$ and $\mathbf{B} .^{7}$ Furthermore, the frontier orbitals for the dication are very similar to the analogous orbitals observed for neutral iminophosphanes containing electron donatin substituents ${ }^{16}$ providing more evidence for the formation of dicationic iminophosphane $\mathbf{5} \mathbf{a}^{2+}$.
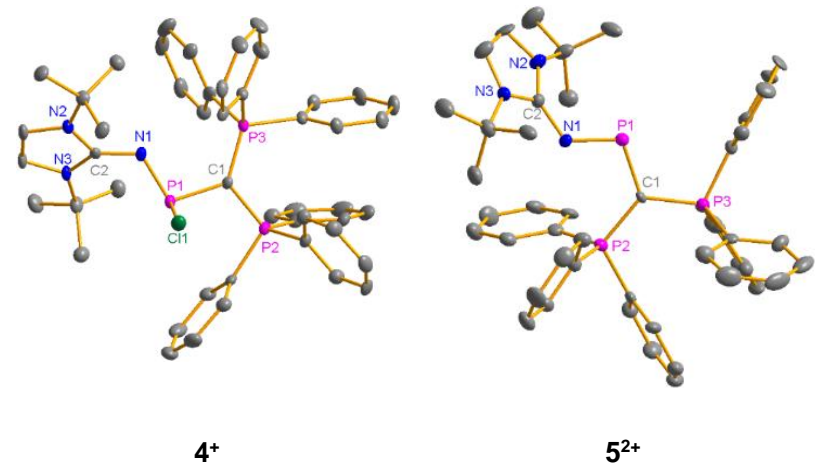

Figure 2. Molecular structures for $\mathbf{4}[\mathrm{Cl}]$ and $\mathbf{5}\left[\mathrm{SbF}_{6}\right]_{2}$ with the ellipsoids drawn at $50 \%$ probability. All hydrogen atoms, solvent molecules and the counterions have been omitted for clarity. Selected bond distances $(\AA)$ and angles $\left({ }^{\circ}\right)$ : 4[Cl]: P1-N1 1.625(4), P1-C1 1.801(4), P1-Cl1 2.3472(16), N1-C2 1.342(5), C1-P1-N1 103.41(19), C2-N1-P1 122.1(3); 5[SbF $]_{2}$ : P1-N1 1.594(6), P1-C1 1.748(7), N1-C2 1.367(8), C1-P1-N1 107.0(3), C2-N1-P1 123.3(5).
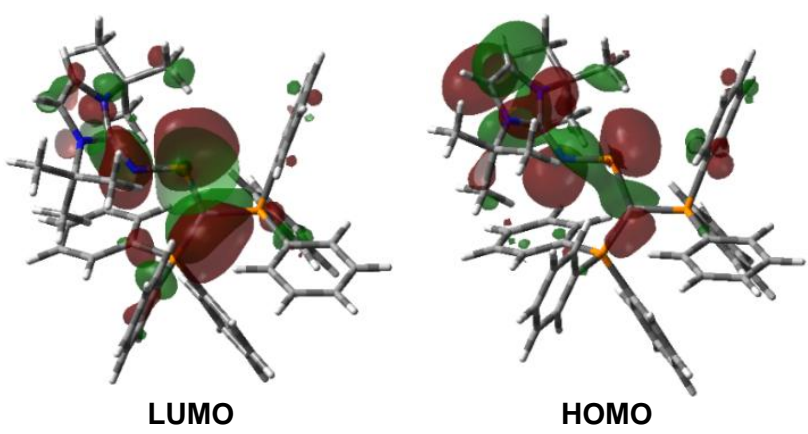

Figure 3. The LUMO and HOMO for $\mathbf{5}^{2+}$.

Nevertheless, the $\sigma$-bond polarization of the P1-C1 and C2-N1 bonds, examined through NBO (natural bond order) analysis, suggested their dative bond character is not negligible. This analysis revealed that the $\mathrm{P} 1-\mathrm{C} 1(68.0 \%$ contribution of $\mathrm{C} 1)$ and $\mathrm{C} 2-\mathrm{N} 1$ (41.3\% contribution of $\mathrm{C} 2$ ) bonds were more polarized towards the donor atoms $(\mathrm{C} 1$ and $\mathrm{C} 2)$ than in the other similar cases $(\mathrm{P} 2-\mathrm{C} 1=$ $61.9 \%$ of $\mathrm{C} 1 ; \mathrm{P} 3-\mathrm{C} 1=61.8 \%$ of $\mathrm{C} 1 ; \mathrm{C} 2-\mathrm{N} 2=37.5 \%$ of $\mathrm{C} 2 ; \mathrm{C} 2-\mathrm{N} 3$ $=37.5 \%$ of C2). ${ }^{22}$ Thus, these observations indicated that the resonance form $\mathbf{5 b}^{2+}$ (a base-stabilized diationic phosphorus mononitride) should not be completely disregarded from the overall description of the newly formed dication.

In summary, the use of a novel carbone-carbene system allowed for successful isolation of the doubly oxidized analogue of A. According to the structural parameters and the nature of the frontier orbitals the most appropriate resonance form for the newly synthesized form would be dicationic iminophosphane $\mathbf{5 a}^{\mathbf{2}}$. However, the dicationic phosphorus mononitride resonance form $\mathbf{5} \mathbf{b}^{2+}$ should also be included in the overall depiction of the dication. Regardless of the bonding description and the nature of $\mathbf{5}^{\mathbf{2}}$, our group is currently exploring the chemistry of this molecule with the focus on its potential use as a delivery vehicle for the PN fragment.

\section{ASSOCIATED CONTENT}

\section{Supporting Information}


Synthetic procedures, details of theoretical calculations and crystal data files. This material is available free of charge via the Internet at http://pubs.acs.org.

\section{AUTHOR INFORMATION}

\section{Corresponding Author}

Email: dvidovic@ntu.edu.sg

\section{Notes}

The authors declare no competing financial interests.

\section{ACKNOWLEDGMENT}

We thank A*STAR (grant \# 1220703062) and acknowledge the funding support for this project from Nanyang Technological University under the Undergraduate Research Experience on CAmpus (URECA) programme (YKL).

Dedicated to Professor Vlatko Vidović on the occasion of his $70^{\text {th }}$ birthday.

\section{REFERENCES}

(1) (a) Dyker, C. A.; Bertrand, G. Science 2008, 321, 1050-1051. (b) Wang, Y.; Robinson, G. H. Dalton Trans. 2012, 41, 337-345. (c) Martin, C. D.; Soleilhavoup, M.; Bertrand, G. Chem. Sci. 2013, 4, 3020-3030. (d) Wang, Y.; Robinson, G. H. Inorg. Chem. 2014, 53, 11815-11832.

(2) (a) Braunschweig, H.; Dewhurst, R. D.; Hammond, K.; Mies, J.; Radacki, K.; Vargas, A. Science 2012, 336, 1420-1422. (b) Böhnke, J.; Braunschweig, H.; Ewing, W. C.; Hörl, C.; Kramer, T.; Krummenacher, I.; Mies, J.; Vargas, A. Angew. Chem. Int. Ed. 2014, 53, 9082-9085.

(3) (a) Li, Y.; Mondal, K. C.; Samuel, P. P.; Zhu, H.; Orben, C. M.; Panneerselvam, S.; Dittrich, B.; Schwederski, B.; Kaim, W.; Mondal, T.; Koley, D.; Roesky, H. W. Angew. Chem. Int. Ed. 2014, 53, 4168-4172. (b) Wu, D.; Li, Y.; Ganguly, R.; Kinjo, R. Chem. Commun. 2014, 50, 1237812381. (c) Wang, Y; Xie, Y.; Wei, P.; King, R. B.; Schaefer III, H. F.; Schleyer, P. v. R.; Robinson, G. H. Science 2008, 321, 1069-1071. (d) Sidiropoulos, A.; Jones, C; Stasch, A.; Klein, S.; Frenking, G. Angew. Chem. Int. Ed. 2009, 48, 9701-9704. (e) Jones, C.; Sidiropoulos, A.; Holzmann, N.; Frenking, G.; Stasch, A. Chem. Commun. 2012, 48, 9855-9857.

(4) (a) Wang, Y.; Xie, Y.; Wei, P.; King, R. B.; Schaefer III, H. F.; Schleyer, P. v. R; Robinson, G. H. J. Am. Chem. Soc. 2008, 130, 1497014971. (b) Back, O; Kuchenbeiser, G. Donnadieu, B.; Bertrand, G. Angew. Chem. Int. Ed. 2009, 48, 5530-5533. (c) Back, O.; Donnadieu, B.; Parameswaran, P.; Frenking, G.; Bertrand, G. Nature Chem. 2010, 2, 369373. (d) Abraham, M. Y.; Wang, Y.; Xie, Y.; Wei, P.; Schaefer III, H. F.; Schleyer, P. v. R.; Robinson, G. H. Chem. Eur. J. 2010, 16, 432-435. (e) Abraham, M. Y.; Wang, Y.; Xie, Y.; Gilliard Jr., R. J.; Wei, P.; Vaccaro, B. J.; Johnson, M. K.; Schaefer, H. F., III; Schleyer, P. v. R.; Robinson, G. H. J. Am. Chem. Soc. 2013, 135, 2486-2488. (f) Kretschmer, R.; Ruiz, D. A.; Moore, C. E.; Rheingold, A. L.; Bertrand, G. Angew. Chem. Int. Ed. 2014, $53,8176-8179$.

(5) (a) Himmel, D.; Krossing, I.; Schnepf, A. Angew. Chem. Int. Ed. 2014, 53, 370-374. (b) Frenking, G. Angew. Chem. Int. Ed. 2014, 53, 60406046. (c) Himmel, D.; Krossing, I.; Schnepf, A. Angew. Chem. Int. Ed. 2014, 53, 6047-6048.

(6) Köppe, R.; Schnöckel, H. Chem. Sci. 2015, 6, 1199-1205.

(7) Kinjo, R.; Donnadieu, B.; Bertrand, G. Angew. Chem. Int. Ed. 2010, 49, 5930-5933.

(8) Back O.; Henry-Ellinger, M.; Martin, C. D.; Martin, D.; Bertrand, G. Angew. Chem. Int. Ed. 2013, 52, 2939-2943.

(9) According to reference 5 the HOMO of $\mathbf{A}$ and the SOMO of $\mathbf{B}$ are anti-boding with respect to the $\mathrm{P}-\mathrm{N}$, so the complete electron depopulation of these orbitals would result in shortening of the P-N bond.

(10) The term carbones has been coined by Frenking et. al.: (a) Tonner, R.; Frenking, G. Angew. Chem. Int. Ed. 2007, 46, 8695-8698. (b) Deshmukh, M. M.; Gadre, S. R.; Tonner, R.; Frenking, G. Phys. Chem. Chem. Phys. 2008, 10, 2298-2301. (c) Tonner, R.; Frenking, G. Chem. Eur. J. 2008, 14, 3260-3272. (d) Takagi, N.; Shimizu, T.; Frenking, G. Chem. Eur. J. 2009, 15, 8593-8604. (e) Frenking, G.; Tonner, R. Pure Appl. Chem.
2009, 81, 597-614. (f) Takagi, N.; Shimizu, T.; Frenking, G. Chem. Eur. J. 2009, 15, 3448-3456. (g) Tonner, R.; Frenking, G. Chem. Eur. J. 2008, 14, 3273-3289.

(11) The first time the concept of carbone was experimentally demonstrated: Dyker, C. A.; Lavallo, V.; Donnadieu, B.; Bertrand, G.; Angew. Chem. Int. Ed. 2008, 47, 3206-3209.

(12) (a) Inés, B.; Patil, M.; Carreras, J.; Goddard, R.; Thiel, W.; Alcarazo, M. Angew. Chem. Int. Ed. 2011, 50, 8400-8403. (b) Khan, S.; Gopakumar, G.; Thiel, W.; Alcarazo, M. Angew. Chem. Int. Ed. 2013, 52, 56445647. (c) Tay, M. Q. Y.; Lu, Y.; Ganguly, R.; Vidović, D. Angew. Chem. Int. Ed. 2013, 52, 3132-3135. (d) Tay, M. Q. Y.; Lu, Y.; Ganguly, R.; Vidović, D. Chem. Eur. J. 2014, 20, 6628-6631. (e) Chen, W.-C.; Lee, C.-Y.; Lin, B.-C.; Hsu, Y.-C.; Shen, J.-S.; Hsu, C.-P.; Yap, G. P. A.; Ong, T.-G. J. Am. Chem. Soc. 2014, 136, 914-917.

(13) Apart from the chloride anion $(40 \%),\left[\mathrm{PO}_{2} \mathrm{Cl}_{2}\right]^{-}(60 \%)$ was also identified (confirmed by ${ }^{31} \mathrm{P}$ NMR spectroscopy) during the structural refinement of $4[\mathrm{Cl}]$. We believe that the source of this anion is partial hydrolysis of this compound during the synthesis.

(14) P-Cl bond elongation has already been observed for ylidyl chlorophosphanes: Jochem, G. Breitsameter, F. Schier, A. Schmidpeter, A. Heteroato. Chem. 1996, 7, 239-247.

(15) (a) Cowley, A. H.; Kemp, R. A. Chem. Rev. 1985, 85, 367-382. (b) Cowley, A. H.; Cushner, M. C.; Lattman, M.; McKee, M. L.; Szobota, J. S.; Wilburn, J. C. Pure Appl. Chem. 1980, 52, 789-797.

(16) (a) Niecke, E.; Gudat, D. Angew. Chem. Int. Ed. Engl. 1991, 30, 217-237. (b) Miqueu, K.; Sotiropoulos, J.-M.; Pfister-Guillouzo, G.; Rudzevich, V. L.; Gonitzka, H.; Lavallo, V.; Romanenko, V. D. Eur. J. Inorg. Chem. 2004, 2289-2300.

(17) Only the absolute values are reported.

(18) March, J. Advanced Organic Chemistry, 4 Edn; John Wiley \& Sons: New York, 1992.

(19) (a) Dielmann, F.; Back, O.; Henry-Ellinger, M.; Jerabek, P.; Frenking, G.; Bertrand, G. Science 2012, 337, 1526-1528. (b) Inoue, S.; Leszczyńska, K. Angew. Chem. Int. Ed. 2012, 51, 8589-8593. (c) Dielmann, F.; Moore, C. E.; Rheingold, A. L.; Bertrand, G. J. Am. Chem. Soc. 2013, 135, 14071-14073. (d) Dielmann, F.; Andrada, D. M.; Frenking, G.; Bertrand, G. J. Am. Chem. Soc. 2014, 136, 3800-3802. (e) Franz, D.; Inoue, S. Chem. Asian J. 2014, 9, 2083-2087. (f) Tamm, M.; Randoll, S.; Herdtweck, E.; Kleigrewe, N.; Kehr, G.; Erker, G.; Rieger, B. Dalton Trans. 2006, 459-467. (g) Beer, S.; Hrib, C. G.; Jones, P. G.; Brandhorst, K.; Grunenberg, J.; Tamm, M. Angew. Chem. Int. Ed. 2007, 46, 8890-8894. (h) Tamm, M.; Petrovic, D.; Randoll, S.; Beer, S.; Bannenberg, T.; Jones, P. G.; Grunenberg, J. Org. Biomol. Chem. 2007, 5, 523-530. (i) Beer, S.; Brandhorst, K.; Hrib, C. G.; Wu, X.; Haberlag, B.; Grunenberg, J.; Jones, P. G.; Tamm, M. Organometallics 2009, 28, 1534-1545. (j) Panda, T. K.; Trambitas, A. G.; Bannenberg, T.; Hrib, C. G.; Randoll, S.; Jones, P. G.; Tamm, M. Inorg. Chem. 2009, 48, 5462-5472. (k) Zhang, S.; Tamm, M.; Nomura, K. Organometallics 2011, 30, 2712-2720. (1) Glöckner, A.; Bannenberg, T.; Daniliuc, C. G.; Jones, P. G.; Tamm, M. Inorg. Chem. 2012, 51, 4368-4378.

(20) Alvarez, S. Dalton Trans. 2013, 42, 8617-8636

(21) (a) Burford, N.; Losier, P.; Macdonald, C.; Kyrimis, V.; Bakshi, P. K.; Cameron, T. S. Inorg. Chem. 1994, 33, 1434-1439. (b) Muthaiah, S.; Do, D. C. H.; Ganguly, R.; Vidović, D. Organometallics 2013, 32, 6718-6724

(22) These observations could also be due to highly polarized nature of the P-N fragment (the NBO partial charges for $\mathrm{P}$ and $\mathrm{N}$ are +1.12 and $0.97 \mathrm{e}$, respectively) and/or hybridization effects which would require highly detailed theoretical investigations which are outside the scope of this work. 
For Table of Contents Only

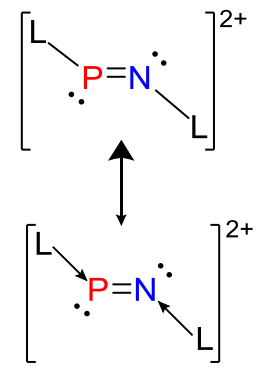

A doubly oxidized form of the previously reported PN-containing molecule has been synthesized. According to the experimental and theoretical investigations the newly prepared compound is best described as dicationic iminophosphine with a small but significant contribution from the corresponding base-stabilized dicationic phosphorus mononitride resonance form. 